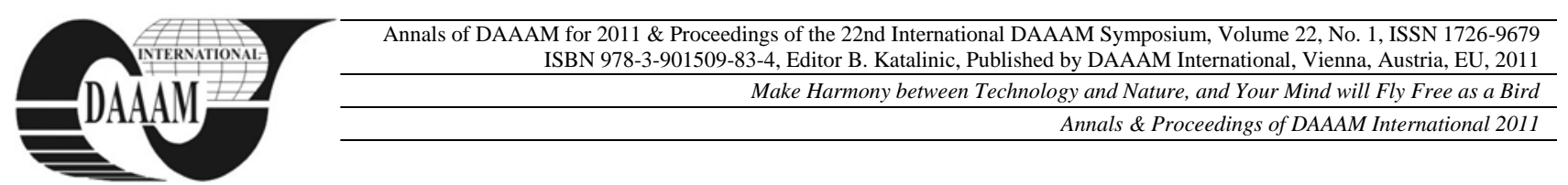

\title{
RESOURCE CONSUMPTION IN LOCAL PUBLIC ADMINISTRATION IN ROMANIA
}

\author{
PREDESCU, L[orena]; NISTOR, N[icoleta] \& ISTUDOR, I[leana] I[ulia]
}

\begin{abstract}
This study which is based on the model of one of the county capitals in Romania is analysing the way in which the public resources from the local budget are allocated with a view to meeting the requirements of the sustainable development. In carrying out the research, we started out from the assumption that out of the multitude of activities carried out by local authorities, the ones which correspond to the sustainable development, in our opinion, are the following: education, health, culture, housing and public development, environmental protection.
\end{abstract}

Key words: local public resources, local budget, local development

\section{INTRODUCTION}

The undertaken research has shown the extent to which the public resources in a municipality budget are allocated with a view to meeting the requirements of the local sustainable development. At present, Romania has a concept of sustainable development, reflected in specific policies and indicators, though we should notice that this mechanism has not been implemented completely at local authorities'level. For the local administration, a strategy based on expenditure, costs, and use of resource consumption analysis is actually an effective tool for control, adjustment and piloting (Niculescu, 2003). The systematic investigation of public spending of a local community will allow us to understand the mechanism of formation of the social and economic benefits of the whole community according to the amount, structure and trends of the different categories of resource consumption. A thorough analysis of the local public expenditure serves to define the public policies of the local authorities (Vacarel and al.,2007). In the field of the financial policies, the most significant concern of the decision-making bodies must be "circumscribing the community's total spending within the resources that can be used ... no community should consume more than it produces" (Vacarel and al.,2007). If a local community does not follow this "axiomatic truth" and works with oversized expenses, then it will have limited development opportunities. The autonomy of the local administration is the right and effective capacity of the local public administration authorities to address and managethe public affairs, under the law, on behalf of and in the interest of the local community they represent (Bistriceanu \& Badea, 2010)

\section{METHODOLOGY}

The complexity and significance of the topic proposed by this study required also an appropiate research methodology in order to fully and consistently reflect both the information in the documents and its perspectives of interpretation. In the case study, we used financial information from the region's annual accounts over the period 2005 to 2010, information that had been included into the reports to the county structures of the Ministry of Finance. To make a resource consumption analysis, we started from the aggregate classification of the expenditure, both functionally and economically within the classification (Local Public Finance Law no. 273, 2006).

\section{COERENCE OF RESOURCE CONSUMPTION WITH SUSTAINABLE DEVELOPMENT REQUIREMENTS}

Development costs are investment expenses that are also called capital expenditure, allocated and approved within the local budget. The analysis of the structure of the capital expenditure shows how the resources are being allocated for activities undertaken by the local authorities. The share of the expenditure out of the revenues, allocated to the local development of the region, shows the concern of the local authorities to guide the budgetary funds towards development.

The structure indicators related to the development expenditure of a region, showing how public resources are being allocated for activities, are the following: the development expenditure rate, the development expenditure rate out of own revenue, the development expenditure per capita, indicators of development expenditure growth, elasticity of development expenditure, annual average growth rate of development expenditure. Following the research carried out based on the data collected from the municipal annual accounts over the period 2005 to 2010 , the analysis of the total development expenditure has shown the following:

- In the above mentioned period, the development expenditure rate recorded a peak in 2007 , i.e. $13.46 \%$ out of the local authority's total expenditure. In 2005, the development expenditure rate out of own revenue was of $5.89 \%$, and in year 2006, it was of $9.89 \%$, representing an increase compared to previous year. In 2008, the development expenditure rate was of $6.43 \%$ out of the total expenditure. In 2009 , it rose to $8.58 \%$ and, in 2010 , it reached a level of $9.14 \%$ out of the total expenditure.

-The rate of the expenditure allocated to local development out of the region's revenues had a peak in 2007, i.e. $25.43 \%$ given that the growth rate of the development expenditure was higher than the growth index of the revenue in the local budget $(168.45>151.92)$. For the other years under review, the following values were recorded: $\mathrm{R}_{2005}=12.84 \%, \mathrm{R}_{2006}=$ $22.94 \%, R_{2008}=12.30 \%, R_{2009}=15.82 \%$ and $R_{2010}=18.29 \%$.

- The capital expenditure per capita had the highest value again in year 2007, i.e. 216.73 lei/ capita and, in 2010, it reached a value of 184.52 lei/capita, representing a decrease by $14.86 \%$ compared to year 2007.

-The growth indices of the development expenditure have been higher than one, except for year 2008, when the allocated amounts decreased by $44.54 \%$.

- The values of the development expenditure elasticity were higher than one in 2006, 2007 and 2009, which shows that the financial resources were allocated to local community development as a priority. 
- The average annual rate of growth of the own revenues in the local budget was of $26.03 \%$, while the annual average rate of growth of the development expenditure was lower, i.e. $17.40 \%$

We believe the actions undertaken by the local authorities which correspond to the sustainable development are the following: education, health, culture, leisure, religion, housing, services, public development and environmental protection. The research that was done, as mentioned before, on the model of one of the county capitals in Romania, based on the data collected from the municipal annual accounts over the period 2005 to 2010 has led to the following results:

- The resources allocated to consumption education have the largest share in the total expenditure of the local authorities, i.e. more than $40 \%$. They are followed by the resources allocated for housing, services and public development, and by the resource consumption for culture, leisure and religion. This means the decentralization process from the central to the local authorities, in what concerns early childhood education, primary education, secondary education was achieved.

- The expenditure for environmental protection and health rank the two of the last places. This means that the decentralization process from central to local authorities has not been finalized yet.

- The expenditure per capita for education ranks the first place with the following values: Expenditure $_{2005}=460.45$ lei/capita, Expenditure ${ }_{2006}=604.41$ lei/ capita, Expenditure $2007=637.72$ lei/capita, Expenditure ${ }_{2008}=823,08$ lei/capita, Expenditure $_{2009}=866.76$ lei/capita, Expenditure ${ }_{2010}=814.85$ lei/capita.

- The expenditure per capita for health has had very low values, as folows: Expenditure $2005=5.24$ lei/capita Expenditure ${ }_{2006}=5.46$ lei/capita, Expenditure ${ }_{2007}=17.70$ lei/capita, Expenditure $2008=0$ lei/capita, Expenditure ${ }_{2009}=$ 11.38 lei/capita, Expenditure $2010=23.57$ lei/capita.

- The expenditure per capita for culture, has had the following values: Expenditure $2005=32.25$ lei/capita Expenditure $_{2006}=93.62$ lei/capita, Expenditure ${ }_{2007}=146.36$ lei/capita, Expenditure $2008=175.70$ lei/capita, Expenditure 2009 $=207.14$ lei/ capita, Expenditure ${ }_{2010}=165.55$ lei $/$ capita.

- The expenditure per capita for housing, services and public development, over the analysed period, has had the following values: Expenditure $2005=236.83$ lei $/$ capita, Expenditure $_{2006}=134.34$ lei/capita, Expenditure ${ }_{2007}=189.05$ lei/ capita, Expenditure $2008=206.01$ lei/capita, Expenditure 2009 $=252.54$ lei/capita, Expenditure $2010=209.12$ lei $/$ capita.

-The expenditure per capita for environmental protection, over the analysed period, is low. Thus, it has had the following values: Expenditure $2005=18.57$ lei/capita, Expenditure ${ }_{2006}=$ 4.39 lei/capita, Expenditure ${ }_{2007}=0.015$ lei/capita, Expenditure $2008=1.87$ lei/capita, Expenditure ${ }_{2009}=55.25$ lei $/$ capita, Expenditure $_{2010}=87.07$ lei/capita.

- The annual average rate of growth of the development expenditure over the analysed period shows the concern of the local authorities to guide the public resources to meeting this goal.

The public resources consumption from the local authorities' budget has increased year by year for activities considered as being coherent with the sustainable development policy, however in the field of environmental protection, in case of the municipality taken into consideration, more attention should be paid by allocating a significant financing from the local budget. The new concept of sustainable economic development includes environment as a fully integrated element into the economic development, development which should hand over the future generations an environment at least equal to that one we have taken from the previous generations. The analysis of the structure of the public spending,according to its economic purposes - allocated to the five fields: education; health; culture, leisure, religion; housing, services, public development and environmental protection, which fall under the local authorities'responsibilities and which, in our opinion, meet the requirements of the local sustainable development policy, highlighted a very important aspect, namely: the activities in these fields are carried out mainly with staff costs, although,during the implementation of these activities,specific expenditure is required also, depending on the nature of the goods and services and, particularly, on the nature of the investment. Following this study, we can say that for all actions undertaken by the local authorities, actions towards the sustainable development of the community, the resource consumption is headed mainly to personnel, goods and services, and less to investment. To increase the esource consumption towards local development, a reliable solution is to attract, as a priority, non-reimbursable European funds, and to change the whole framework of property taxation system by taking into consideration the market value (SAR Policy Brief no. 54 August 2011) that could "double" the revenues into the local budget with a view to allocating them to investment. At present, sustainable development at local level should be given primary attention because, if transparently presented to population, it brings confidence and hopes that the standard of living will increase.

\section{CONCLUSION}

This part of the study demonstrates an unquestionable truth, that in Romania, the actions undertaken by local authorities under the law are carried out mainly with human and material resources and less with resources allocated to local community development. The limits of our research are set by the fact that the spending analysis is focused mainly to the past, to the disadvantage of the forecast, strategic approaches, and there are difficulties in highlighting the real causes of variations in resource consumption.

\section{ACKNOWLEDGEMENTS}

This study was prepared within the scientific research project, which is co-financed by the European Social Fund through the Operational Programme for Human Resources Development 2007-2013, Priority Axis 1 "Education and training in support of economic growth and development of knowledge-based society", Key area of intervention 1.5. "Doctoral and postdoctoral programs in support of research", Project title "Doctoral scholarships, the prerequisite for increased competitiveness in scientific research skills", Project ID 63269 .

\section{REFERENCES}

Bistriceanu Gh., Badea L. (2010). Romania's state budget, Bibliotheca Publishing House, ISBN 978-973-712-5-7-1, Targoviste

Niculescu M.(2003). Economic diagnosis, vol.1, Economica Publishing House,ISBN 973-590-721-6 , Bucharest

Vacarel I. and collective (2007). Public Finances, Didactica and Pedagogica Publishing House, ISBN 978-973-30-19985, Bucharest

***(2011)http://www.sar.org.ro/files/Policy\%20memo54.pdfRomanian Academic Society, Accessed on:2011-09-05

***(2006) Local Public Finance Law no. 273, Official Gazzette, Part I, nr. 618 of 18th July 2006

***Municipal budget execution accounts for the period 20052010, Targoviste. 